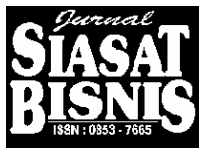

Hal.: $81-91$

\title{
PARADIGMA BARU PENINGKATAN KINERJA BADAN USAHA MILIK DAERAH (BUMD)
}

\author{
Syafaruddin Alwi \\ Fakultas Ekonomi \\ Universitas Islam Indonesia
}

\begin{abstract}
The Regional Autonomy policy of the government in Indonesia will give a crucial impact for a regional enterprise owned by the regional government (in short BUMD). In the context of regional autonomy era, the BUMD will be playing a very important role in increasing of financial contribution to the real regional income of the region. The problems are, how will this mission be achieved, and what is the business strategy for improving the regional enterprise performance? By aligning human resource strategy, to business strategy, these problems will be analyzed. Strategic business goals should never be considered without linking them with human resource strategy. Based on human resource perspective, the BUMD will therefore be successful to achieve the mission, when it is managed by professional managers and skilled employees. The BUMD must consider to change organization structure, redesigning job, replace unskilled employee, in order to develop organizational performance.
\end{abstract}

Key words: Badan Usaha Milik Daerah (BUMD), regional enterprise performance

\section{PENDAHULUAN}

Perusahan-perusahaan daerah (BUMD) atau yang dikenal sebagai badan usaha milik daerah (BUMD), jarang sekali menjadi sorotan media massa. Hal ini kemungkinan disebabkan kurang menarik untuk dijadikan berita sebagai wacana publik. Sebenarnya banyak asset daerah di Indonesia ini, kalau diteliti memiliki potensi yang tinggi untuk dikelola dan dikembangkan dalam rangka peningkatan pendapatan asli daerah yang bersangkutan. Beberapa pemerintah daerah seperti kabupaten Boyolali dan kabupaten Magelang di propinsi Jawa Tengah dan Daerah Istimewa Yogyakarta (DIY) telah melakukan berbagai tindakan dalam bentuk kebijakan tertentu untuk mengembangkan dan memberdayakan BUMD yang dimiliki.

Dalam upaya itu, sebagai ilustrasi, seluruh BUMD milik pemerintah kabupaten Boyolali akan diserahkan pengelolaan manajerialnya kepada para profesional diluar pegawai negeri sipil (PNS) untuk mendorong pertumbuhan BUMD yang dinilai kurang berkembang (KR, 3 Maret 2001). Pemda kabupaten Boyolali memiliki beberapa BUMD seperti percetakan, apotik, perusahaan air minum (PDAM), bank pasar dan lain-lain. BUMD kabupaten Magelang khususnya perusahaan daerah air minum (PDAM) 
dengan tujuan yang sama yaitu peningkatan $P A D$, telah mengambil langkah-langkah yang mengarah kepada profit oriented (KR 6 November 2000). Sementara itu pemerintah DIY selain mempertahankan BUMD yang ada, akan mengembangkan BUMD baru. Sekarang ini sedang dikaji kemungkinan itu dan bahkan sedang dikaji juga kemungkinan penggabungan antara BUMD-BUMD yang baru dengan BUMD yang lama. Pengkajian ini dilakukan dalam rangka DIY meningkatkan otonomi daerah (KR 6 Februari 2001).

Pemda Jawa Tengah memiliki tidak kurang dari 19 unit perusahaan dalam berbagai bidang usaha mulai dari perkebunan, perhotelan, pabrik es, keramik sampai apotik yang tergabung dalam satu manajemen yaitu, manajemen BUMD. Pihak manajemen BUMD Jawa Tengah saat ini berjuang untuk meletakkan BUMD pada peran yang layak sebagai kontributor peningkatan PAD. Peran ini belum memadai jika dilihat dari peroblem yang umumnya dihadapi BUMD yaitu, kinerja keuangan yang masih rendah karena struktur biaya yang masih tinggi, persoalan manajemen bisnis dan profesionalitas SDM.

Kenyataan ini menarik untuk dikaji, mengingat hampir semua propinsi atau kabupaten di Indonesia memiliki BUMD. Tetapi seringkali diberitakan melalui media massa bahwa BUMD pada umumnya menghadapi berbagai kendala klasik dalam pengoperasiannya seperti masalah modal, sistem manajemen dan sumber daya manusia.

Berkaitan dengan kebijakan otonomi yang mulai berjalan bulan Januari 2001, BUMD memiliki peran yang diharapkan dapat menunjang peningkatan pendapatan asli daerah (PAD). Peran itu tidak mudah terwujud karena badan-badan usaha milik negara (BUMN) apalagi BUMD, selama ini dikelola dalam iklim birokrasi, tidak efisien dan kurang profesional. Melihat berbagai persoalan BUMD ini, dalam rangka otonomi, sangat relevan dibahas mengingat kebutuhan daerah akan sumber-sumber daya keuangan yang mampu menunjang peningkatan PAD sangat mendesak.

\section{PROBLEM PENGELOLAAN BUMD}

Karyawan yang bekerja pada BUMD umumnya berstatus pegawai negeri sipil (PNS). Kinerja PNS termasuk karyawan BUMD, seringkali mendapat kritik dari masyarakat yang dilayani, karena dalam menjalankan tugas-tugasnya cenderung tidak profesional. Dalam iklim kerja birokratik, seorang bawahan cenderung menunggu petunjuk, sebelum mengambil keputusan. Akibatnya kreativitas kurang berkembang. Ide-ide inovatif, tidak muncul. Sifat entrepreneuership pada manajemen BUMD pada umumnya kurang berkembang. Ambil contoh masih menurut sumber KR, bank pasar di Boyolali banyak dijabat oleh para pensiunan. Walaupun itu belum tentu 
buruk, tetapi dapat ditebak, sifat profesional dan entrepreneuership manajemen badan usaha tidak akan berkembang.

Persoalan modal, memang menjadi hambatan bagi BUMD, karena selama ini, BUMD pada umumnya tidak bisa secara bebas mengambil kebijakan keuangan, kecuali atas persetujuan pemerintah daerah. Keterikatan dengan peraturan daerah sangat ketat. Oleh sebab itu, dalam pengembangan BUMD, agar lembaga bisnis ini mampu berperan secara mandiri dalam meningkatkan pendapatan asli daerah, kendala-kendala seperti peraturan, rendahnya kualitas SDM, cara-cara kerja birokratik yang menghambat inovasi dan sebagainya, perlu diatasi. Dengan kendala-kendala seperti itu, sangat sulit bagi manajemen BUMD untuk melakukan terobosanterobosan terutama dalam penyehatan dan pengembangan perusahaan.

\section{OTONOMI DAERAH}

Dalam era reformasi ini, masalah keseimbangan keuangan antara pusat dan daerah menjadi mencuat kepermukaan secara tajam karena selama pemerintahan orde baru, dianggap telah terjadi ketidak-seimbangan distribusi keuangan khususnya antara pusat dan daerah. Daerah-daerah (baca propinsi) tertentu terutama diluar pulau Jawa memiliki sumbersumber daya alam (natural resources) yang kaya yang dalam porsi lebih besar telah mengalir ke pusat sehingga daerah-daerah yang bersangkutan tidak dapat menikmati hasil-hasil sumber daya alam tersebut untuk keperluan yang lebih besar bagi pembangunan daerah.

Keadaan ini dianggap "tidak adil" sehingga menjadi salah satu isu penting dalan era reformasi ini selain isu pemberantasanan KKN. MPR RI cukup tanggap sehingga dalam sidang istimewa MPR tahun 1998, MPR mengeluarkan TAP Nomor XV tentang penyelenggaraan otonomi daerah, pengaturan, pembagian dan pemanfaatan sumber daya nasional yang berkeadilan, serta perimbangan keuangan pusat dan daerah dalam rangka negara kesatuan RI.

Masalah otonomi daerah yang berdasarkan UU No. 5 tahun 1974 di titik beratkan pada daerah tingkat II, sebenarnya tidak hanya didasarkan pada pertimbangan politis semata tetapi juga didasarkan pada pertimbangan ekonomi, sosial, budaya serta pertahanan dan keamanan di daerah. Dalam kenyataannya, pelaksanaan otonomi daerah yang dititik beratkan pada daerah tingkat II ini, belum dapat dilaksanakan sepenuhnya.

Salah satu masalah otonomi daerah yang penting adalah pengelolaan keuangan daerah termasuk penggalian sumber-sumber pendapatan asli daerah dan pemanfaatannya bagi pembangunan daerah. Peran ini diharapkan dilakukan oleh badan-badan usaha milik pemerintah daerah. Masih banyak daerah tingkat satu yang memiliki BUMD yang 
masih survive termasuk di Jawa Tengah, Jawa Timur dan DIY. Tetapi perusahan-perusahaan itu, pada umumnya kurang berkembang. Dari seminar nasional tentang otonomi daerah yang diselenggarakan oleh UII tahun 1998 dapat diketahui bahwa BUMD pada umumnya memiliki masalah-masalah yang crucial, salah satunya adalah rendahnya kinerja keuangan.

\section{LANGKAH-LANGKAH STRATEJIK}

Untuk meletakkan peran BUMD seperti yang telah dikemukakan, diperlukan langkah-langkah stratejik tertentu. Tetapi langkah-langkah ini mungkin berbeda bagi beberapa BUMD karena masing-masing pemeritah daerah tentu memiliki kebijakan yang berbeda. Misalnya, pemerintah daerah Jawa Tengah, mengambil langkah dimulai dari mengintegrasikan manajemen unit-unit bisnis yang dimiliki menjadi satu kesatuan manajemen BUMD. DIY nampaknya akan mengembangkan BUMD-BUMD yang mandiri bagi setiap unit. Implikasi terhadap manajemen BUMD akan berbeda pula.

Tetapi setiap pimpinan BUMD perlu melakukan langkah awal yaitu mendiagnosis kemampuan organisasi BUMD tersebut dan bagaimana mengoperasikan organisasi tersebut secara efektif. Organizational diagnosis (OD) adalah proses penilaian yang sistematis dan keterkaitan antara peraktek-peraktek organisasi dengan tujuan-tujuan bisnis (Ulrich, 1998). OD merupakan jembatan antara strategi bisnis dengan strategi SDM. Di sini ada proses yang menunjukkan bagaimana strategi-strategi bisnis yang akan dijalankan dioperasionalisasikan dalam peraktek-peraktek organisasi untuk mencapai tujuan-tujuan bisnis stratejik yang telah dirumuskan (lihat gambar 1).

\section{Gambar 1. Diagnosis Organisasi}

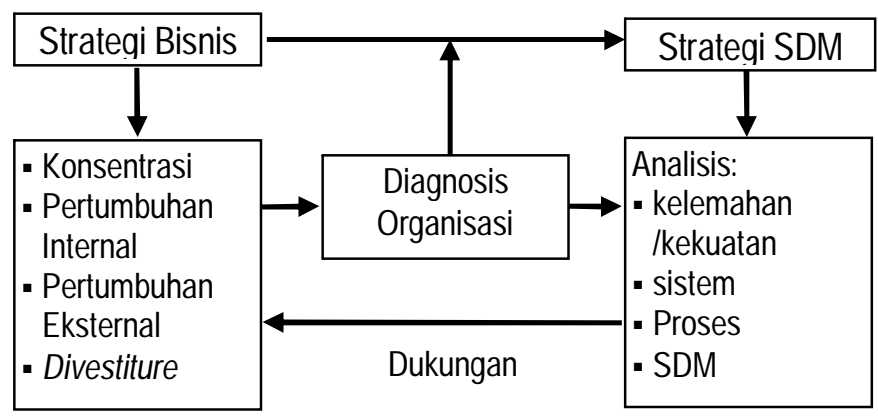

Diagnosis ini dilakukan dengan mengidentifikasi faktor-faktor eksternal dan implikasinya terhadap manajemen BUMD. Setelah itu 
diformulasikan strategi bisnis apa yang digunakan dan strategi SDM yang bagaimana yang dikembangkan untuk mendukung implimentasi strategi bisnis itu.

Diagnosis organisasi menyangkut paling tidak empat aspek penting yaitu, analisis tentang kekuatan dan kelemahan organisasi, kemampuan organisasi, proses dan kesiapan SDM organisasi dalam mendukung berbagai strategi bisnis yang terpilih. Analisis ini sangat penting karena setiap perubahan strategi bisnis, akan merubah strategi SDMnya dan akan terjadi pula perubahan pada berbagai aspek tersebut

\section{Analisis Kekuatan Dan Kelemahan}

Mengkaji kekuatan atau kelemahan organisasi sebagai langkah awal dalam mendiagnosis organisasi ditujukan untuk mengetahui sejauh mana resources yang dimiliki organisasi mendukung efektivitas strategi organisasi dan sejauh mana kelemahan-kelemahan yang dimiliki yang potensial menghambat efektivitas strategi.

\section{Kemampuan Organisasi}

Organisasi ditopang oleh sejumlah sistem. Sistem ibarat tiang penyangga atau pilar yang menjamin eksistensi organisasi. Pengoperasian organisasi melalui dukungan sistem yang efektif adalah esensial bagi pencapaian tujuan organisasi. McKinsey memperkenalkan konsep $7 \mathrm{~S}$ sebagai pilar organisasi yaitu, strategi, struktur, sistems, staff, style, skill, dan superordinate goals. Ini berarti, organisasi akan efektif bila ketujuh $\mathbf{S}$ tersebut didisain dan diintegrasikan secara harmonis sebagai "arsitektur" organisasi (organizatinal architecture).

Beranjak dari perspektif itu, manajemen BUMD dapat melakukan diagnosis organisasi melalui langkah-langkah yang sama. Pengalaman penulis dengan BUMD Jawa tengah menarik untuk dikemukakan yang barangkali juga bisa dipertimbangkan oleh BUMD di daerah lain sepanjang karakteritik kondisi dan masalahnya sama. BUMD Jawa Tengah jauh sebelum pelaksanaan otonomi telah mengambil kebijakan untuk menyatukan unit-unit perusahaan menjadi satu kesatuan manajemen. Akibat dari kebijakan ini pihak Direksi melakukan berbagai perubahan dalam manajemen perusahaan. Perubahan lingkungan eksternal yang mendorong perubahan tersebut menyangkut :

- Kebijakan pemerintah

- Penerapan otonomi daerah

a Reformasi politik

口 Krisis ekonomi yang berkepanjangan

Perubahan lingkungan seperti itu membawa akibat tertentu bagi BUMD yang dapat diidentifikasi sebagai mana dicantumkan dalam tabel 1. 
Tabel 1. Faktor perubahan dan implikasi yang ditimbukan

\begin{tabular}{|l|l|}
\hline \multicolumn{1}{|c|}{ Faktor Perubahan } & \multicolumn{1}{c|}{ Implikasi } \\
\hline $\begin{array}{l}\text { Kebijakan pemerintah tentang } \\
\text { BUMD }\end{array}$ & $\begin{array}{l}\text { Perubahan organisasi menjadi satu kesatuan. Akibatnya struktur } \\
\text { organisasi mengalami perubahan }\end{array}$ \\
\hline Penerapan otonomi daerah & $\begin{array}{l}\text { Menempatkan BUMD untuk berperan sebagai salah satu kontributor } \\
\text { penting bagi peningkatan PAD }\end{array}$ \\
\hline Reformasi politik & $\begin{array}{l}\text { Manajemen BUMD menjadi terbuka terhadap kritik masyarakat, } \\
\text { intervensi publik dan tuntutan DPRD }\end{array}$ \\
\hline Krisis ekonomi & $\begin{array}{l}\text { Tingkat bunga tinggi sehingga tantangan BUMD dalam meningkatkan } \\
\text { kemampuan memperoleh laba tinggi. Tambahan modal tidak mudah } \\
\text { diperoleh. }\end{array}$ \\
\hline
\end{tabular}

Dengan melihat tabel 1, dapat dikemukakan bahwa pihak manajemen BUMD harus melakukan perubahan terutama perubahan yang menyangkut sistem dan proses. Sistem berkaitan dengan pilar-pilar organisasi perusahaan mulai dari visi, misi, tujuan, strategi, struktur, kultur, SDM, dan sebagainya.

\section{PILAR ORGANISASI}

Organisasi perusahaan itu ibarat bangunan. Bangunan memiliki pilarpilar seperti tiang dan kerangka bangunan. Sedangkan proses berkaitan dengan bagaimana BUMD ini dijalankan atau dikelola. Bagaimana pilarpilar itu dibentuk tergantung paradigma apa yang akan kita pakai. Yang jelas, BUMD saat ini menghadapi paradigma perubahan sebagai akibat tekanan yang tertera pada tabel 1. Perubahan yang perlu dilakukan pada pilar organisasi BUMD antara lain adalah :

- Disain dan prinsip organisasi

- Budaya kerja

- Orientasi strategi bisnis

- Sumber-sumber

a SDM

- Kebijakan penempatan karyawan

Bagaimana karakteristik dari pilar-pilar itu waktu yang lalu dan perubahan yang terjadi atau perubahan yang diharapkan dan apa implikasi stratejiknya terhadap manajemen BUMD, dapat dilihat pada matrik atau tabel 2 berikut ini. Berdasarkan tabel 2, Direksi BUMD dapat melakukan perubahan secara terarah dan sistematis. 
Tabel 2. Karakteristik Perusahaan dan Implikasi Stratejik

\begin{tabular}{|l|l|l|l|}
\hline \multicolumn{1}{|c|}{ Variabel } & \multicolumn{1}{|c|}{$\begin{array}{c}\text { Karakteristik } \\
\text { Lalu }\end{array}$} & \multicolumn{1}{c|}{$\begin{array}{c}\text { Karakteristik } \\
\text { Sekarang/Yang diharapkan }\end{array}$} & \multicolumn{1}{|c|}{ Implikasi Stratejik } \\
\hline Disain Organisasi & $\begin{array}{l}\text { Unit-unit usaha } \\
\text { bersifat parsial }\end{array}$ & $\begin{array}{l}\text { Satu Kesatuan Perusahaan } \\
\text { Daerah }\end{array}$ & Struktur organisasi terpadu \\
\hline Prinsip organisasi & Otonomi unit & Satu kesatuan stratejik & $\begin{array}{l}\text { Sistem desentralisasi atau } \\
\text { lateral }\end{array}$ \\
\hline Budaya kerja & Birokrasi & Prestasi & $\begin{array}{l}\text { SDM berwatak } \\
\text { entrepreneuer }\end{array}$ \\
\hline $\begin{array}{l}\text { Sistem } \\
\text { kompensasi }\end{array}$ & $\begin{array}{l}\text { Peraturan } \\
\text { pemerintah }\end{array}$ & Peraturan perusahaan & $\begin{array}{l}\text { Sistem penilaian kinerja } \\
\text { berdasarkan prestasi atau } \\
\text { hasil }\end{array}$ \\
\hline $\begin{array}{l}\text { Orientasi strategi } \\
\text { organisasi }\end{array}$ & Bertahan/survive & Bertahan dan mencari peluang & $\begin{array}{l}\text { Efisiensi Biaya dan } \\
\text { Peningkatan market } \\
\text { share/perluasan pasar }\end{array}$ \\
\hline Sumber modal & $\begin{array}{l}\text { Eksternal/ } \\
\text { Pemerintah }\end{array}$ & $\begin{array}{l}\text { Internal/akumulasi cadangan } \\
\text { laba perusahaan. Eksternal, } \\
\text { kredit perbankan }\end{array}$ & Cara kerja profesional \\
\hline Strategi SDM & $\begin{array}{l}\text { Mempertahankan } \\
\text { karyawan yang ada } \\
\text { (Retensi) }\end{array}$ & $\begin{array}{l}\text { Pengembangan karyawan } \\
\text { potensial dan penarikan } \\
\text { tenaga baru yang siap pakai }\end{array}$ & $\begin{array}{l}\text { Sistem kompensasi perlu } \\
\text { diperbaiki dan menggunakan } \\
\text { kemungkinan sistem part time }\end{array}$ \\
\hline $\begin{array}{l}\text { Purang berdasarkan } \\
\text { prinsip the right man } \\
\text { on the right job }\end{array}$ & The right man on the right job & Replacement \\
\hline
\end{tabular}

\section{Disain Dan Prinsip Organisasi}

Pemerintah daerah telah mengambil kebijakan dalam bentuk perubahan organisasi BUMD dari otonomi unit-unit usaha menjadi satu kesatuan organisasi. Implikasi kebijakan ini, struktur organisasi mengalami perubahan. Tentunya perubahan struktur ini harus dicegah agar jangan sampai kreativitas unit-unit usaha dalam berbagai kelompok usaha, menjadi terhambat. Untuk itu prinsip organisasi harus ditegaskan bahwa sistem kerja organisasi berdasarkan asas desentralisasi. Organisasi harus bersifat lateral sehingga manajemen masing-masing unit dapat melakukan proses bisnis dengan baik tetapi dalam konteks pencapaian tujuan dan target yang ditetapkan oleh BUMD (manajemen tingkat pusat). Bagi BUMD yang tidak disatukan menjadi satu kesatuan mana-jemen, tidak mengalami masalah desentralisasi karena organsasinya sudah bersifat mandiri.

\section{Budaya Kerja}

Untuk bekerja lebih baik, budaya kerja yang lalu yang bersifat birokratik, harus mengalami perubahan kearah budaya prestasi. Implikasinya adalah, diperlukan SDM yang berwatak entrepreneuer. Watak selalu 
diperdebatkan apakah bisa diubah. Untuk menumbuhkan budaya kerja prestasi, tidak mudah merubah perilaku dan sikap karyawan yang sudah dipengaruhi oleh budaya birokrasi. Oleh sebab itu, kebijakan yang diambil oleh Pemerintah daerah seperti yang telah disampaikan dimuka, yaitu akan menarik PNS dari manajemen BUMD dan menyerahkan pada para profesional, dapat dipahami.

\section{Sistem Kompensasi}

Sistem kompensasi tidak mudah diubah karena masih terikat dengan peraturan pemerintah. Tetapi sebagai wacana, perlu dipertimbangkan dalam jangka panjang, perubahan sistem kompensasi yang ditetapkan oleh BUMD yaitu penerapan sistem yang berdasarkan prestasi. Pada tahap sekarang ini yang paling mungkin adalah menerapkan sistem insentif atau bonus.

\section{Strategi Organisasi}

BUMD saat ini masih berada pada posisi sebagai organisasi yang bertahan hidup. BUMD masih survive. Tetapi dalam jangka panjang jika ingin berperan sebagai kontributor PAD, harus bergerak kearah perusahaan yang juga mencari peluang-peluang bisnis. Implikasinya, BUMD harus berusaha melakukan efisiensi biaya sembari meningkatkan market sharenya.

\section{Sumber Modal}

Manajemen BUMD menyadari bahwa untuk meningkatkan kemampuan perusahaan, mungkin diperlukan modal tambahan. Tetapi ini sulit dilakukan mengingat pemerintah daerah juga menghadapi kendala tersendiri untuk memenuhi ini. Disamping itu, kurang layak apabila dalam era perubahan ini, BUMD menggantungkan modal dari pemerintah. Oleh sebab itu, perlu pemikiran agar cara-cara kerja pimpinan dan karyawan yang selama ini cenderung bersifat birokrasi administratif diubah kearah cara-cara kerja yang profesional. Berdasarkan ketentuan Bapepam, sebenarnya pemerintah daerah diberi kesempatan untuk memasuki pasar modal. Sudah tentu jika BUMD tersebut memenuhi syarat-syarat yang telah ditetapkan.

Manajemen BUMD tidak bisa hanya mengandalkan tambahan dana dari pemerintah daerah semata melainkan harus mempertimbangkan mencari terobosan sumber dana dengan mempertimbangkan kemungkinan privatisasi agar terlepas dari kontrol dan intervensi langsung dari birokrasi. Dengan demikian BUMD akan dapat membangun pengelolaan bisnis yang profesional dan transparan. Mungkin sekali BUMD melakukan aliansialiansi strategis dengan BUMN. 


\section{Strategi SDM}

Untuk menopang tujuan-tujuan bisnis secara profesional, perlu dipertimbangkan oleh pihak manajemen, agar merekrut tenaga profesional yang kalau perlu bersifat part time atau kontrak guna mengatasi masalah SDM yang crucial. Harus diakui bahwa kualitas SDM BUMD saat ini kebanyakan berlatar belakang pendidikan menengah ke bawah. Hanya ada beberapa orang yang memiliki latar belakang pendidikan tinggi. Ini menjadi hambatan yang serius bagi manajemen untuk memajukan perusahaan.

\section{Kebijakan Penempatan}

Penempatan karyawan pada posisi jabatan, dahulu barangkali kurang mendasarkan pada prinsip the right man on the right job. Pada saat ini dan yang akan datang, penempatan harus berdasarkan prinsip tersebut. Saat ini perlu dipertimbangkan untuk melakukan penggantian terhadap personil yang sama sekali tidak kapabel menjalankan fungsinya.

Karyawan bagi organisasi bisnis bukanlah beban melainkan tulang pungung. SDM adalah partner stratejik. SDM merupakan salah satu dari sumber keunggulan kompetitif bagi organisasi. Pandangan ini juga diperkuat oleh Sheila Cane (1996) yang menyatakan bahwa hanya organisasi-organisasi yang meletakkan prioritas pada strategi SDM sebagai strategi bisnislah yang akan memiliki kekuatan untuk menjadi atau tetap sebagai kelas utama. Ini berarti, strategi bisnis hanya dicapai bila orangorang dalam organisasi yang bertanggung jawab menjalankan strategi tersebut, memiliki komitmen dan keahlian untuk melaksanakan strategi itu dengan baik.

\section{OPERASIONALISASI ORGANISASI}

Setelah dilakukan penataan organisasi langkah selanjutnya adalah bagaimana membuat organisasi BUMD mampu menjalankan proses bisnisnya. Secara teoritik ada enam faktor yang menentukan bagaimana organisasi digerakkan (Ulrich: 68).

\section{- Share mindset \\ - Kompetensi \\ - Konsekuensi \\ - Governance \\ - Proses kerja dan kapasitas perubahan \\ - Kepemimpinan}

Share mindset menunjukkan identitas organisasi dan kultur yang akan dikembangkan. Dalam kaitan ini, BUMD harus berani melakukan pilihan bahwa BUMD adalah perusahaan yang profit oriented dan karena itu budaya yang dikembangkan adalah budaya kualitas dan prestasi. 
Pilihan ini mengandung konsekuansi kebutuhan akan kemampuan, keahlian dan pengetahuan dari karyawan (kompetensi) yang mungkin berbeda dengan karakteristik karyawan yang ada sekarang. Konsekuensi lain adalah sistem kompensasi, sistem penilaian kinerja juga harus dilakukan perubahan. Governance menunjukkan bagaimana manajemen BUMD menciptakan proses pengambilan keputusan yang efektif dan efisien melalui dukungan sistem komunikasi yang efektif.

Demikian pula dengan proses kerja dalam organisasi. Manajemen harus mampu melakukan perubahan bila diperlukan (capacity for change) dan selalu dalam proses pembelajaran. Pada akhirnya kepemimpinan akan menentukan keberhasilan organisasi. Pimpinan BUMD harus berjiwa manajer yaitu sebagai pemimpin ia harus mampu mengelola semua resources yang ada dalam perusahaan secara efektif dan efisien.

\section{PENUTUP}

Masalah yang dihadapi oleh BUMD sama halnya dengan BUMN. Dalam upaya memberdayakan BUMD maka Pemerintah daerah dan pihak manajemen harus meredefinisi kembali peran BUMD sebagai korporasi yang mampu mencetak laba, mendukung peningkatan pendapatan daerah, dan menjadi akselerator pertumbuhan ekonomi wilayah. Pada akhirnya sejauhmana BUMD berhasil mengemban misi peningkatan PAD bagi suatu daerah, tergantung pada political pemerintah daerah untuk konsekuen dan konsisten mendesentralisasikan manajemen BUMD kepada para profesional yang bersedia untuk itu. Political will seperti itu cukup berat konsekuensinya karena akan menyangkut persoalan pemindahan karyawan atau perubahan dalam status kepegawaiannya jika karyawan yang ada berstatus PNS. Bagaimanapun BUMD jika berhasil dikelola dan dikembangkan akan menjadi salah satu andalan bagi pemasukan PAD suatu daerah.

Kiat-kiat yang mungkin dipertimbangkan oleh BUMD, dengan menggunakan pendekatan SDM sebagai keunggulan kompetitif, terutama kaitannya dengan peran BUMD dalam penggalian pendapatan asli daerah, antara lain, menyehatkan dan mengembangkan BUMD dengan melakukan berbagai perubahan. Perubahan itu misalnya, perubahan terhadap struktur organisasi, agar lebih bersifat fungsional, dan melakukan job redesign, guna meningkatkan motivasi dan menunjang proses kerja secara efektif. Perlu dipertimbangkan pula, rekrutmen karyawan dari sumber internal melalui metode job posting, yaitu, mengumumkan secara terbuka jabatan yang tersedia dan terbuka bagi semua karyawan yang memenuhi syarat untuk jabatan tersebut, atau merekrut tenaga baru yang diperlukan dengan sistem kontrak. Penempatan karyawan, tidak lagi semata-mata berdasarkan pertimbangan pengalaman, tetapi juga keahlian dan kemampuan. Semua 
kiat tersebut, ditujukan untuk memungkinkan para karyawan terutama karyawan pada level manajer, melakukan langkah-langkah stratejik dalam penyehatan dan pengembangan perusahaan.

\section{DAFTAR PUSTAKA}

Beverly L. Kaye (1997), UP Is Not Only Way, A Guide To Developing Workeforce Talent, Davies Black Publishing.

Cane Sheila (1996, p. 157), Kaizen Strategies for Winning Through Peole, Pitman Publishing.

Gomez-Mejia, Balkin, Cardy (1998), Managing Human Resources, Second Edition, Prentice-Hall Inc.

Greer Charles R. (1995), Strategy and Human Resources, Konsep Sonnenfeld dan Maury Peiperl tentang Tipologi Sistem Karir, Prentice Hall Inc.

Kedaulatan Rakyat, 6 November 2000 6 Februari 2001

3 Maret 2001

Katz Robert L. (1974), Skill of an Effective Administrator, Harvard Business Review, Vo. 52, p 94.

Noe et all (2000), Human Resource management; Gaining a Competitive Advantage, Third Edition, McGraw-Hill Companies.

Ulrich Dave (1997), Human Resource Champions, HBS Press, Boston, Massachusets.

Walker James. W (1992), Human resource Strategy, Mc Graw-Hill International Editions. 